\title{
VÍDEOS EDUCACIONAIS E A IMPORTÂNCIA DOS MODOS DE ENDEREÇAMENTO
}

\section{Clinger Cleir Silva Bernardes}

Instituto Federal do Espírito Santo

E-mail: clinger.bernardes@ifes.edu.br

\section{LUIZ Augusto CoImBra de REZENDE Filho}

Universidade Federal do Rio de Janeiro

E-mail: luizrezende@ufrj.br

\begin{abstract}
RESUMO
O uso de vídeos é prática rotineira na Educação Científica e Tecnológica. Docentes e estudantes usam vídeos disponíveis em diversas plataformas ou produzem vídeos específicos para alguma ação pedagógica. Neste artigo, apresentamos o conceito de modos de endereçamento de vídeos a partir do paradigma do espectador, por meio da discussão e da análise da construção do endereçamento de algumas obras audiovisuais. Nosso objetivo é evidenciar a importância do endereçamento nas práticas pedagógicas com produções audiovisuais. A consideração do endereçamento é fator decisivo na boa recepção de vídeos e, consequentemente, no êxito de ações educacionais que os utilizem.
\end{abstract}

\section{PALAVRAS-ChAVE:}

Modos de Endereçamento; Vídeos educacionais; Educação Científica e Tecnológica.

\section{EDUCATIONAL VIDEOS AND THE IMPORTANCE OF MODES OF ADDRESS}

\begin{abstract}
The use of videos is a routine practice in Science and Technology Education. Teachers and students use videos available on various platforms or produce specific videos for educational purposes. In this article we present the concept of modes of address from the viewer's paradigm, by discussing research results and analyzing the construction of the address of some audiovisual productions. Our goal is to highlight the importance of address in pedagogical practices with audiovisual productions. We argue, therefore, that the consideration of address is a decisive factor in the adequate reception of videos and, consequently, in the success of educational actions that use them.
\end{abstract}

\section{KEYWORDS:}

Modes of Address; Educational vídeos; Scientific and Technological Education.

\section{INTRODUÇÃO}

Os Estudos Culturais (Cultural Studies) abarcam uma diversidade de posições metodológicas e tradições teóricas, geralmente interdisciplinares, transdisciplinares e, 
por vezes, até contradisciplinares, com uma concepção ampla de cultura (Nelson et al, 1995, p.12). Eles têm sido largamente utilizados, principalmente por teóricos de esquerda, como uma promessa intelectual, pois buscam entender os mais diversos interesses políticos e sociais de um mundo com fronteiras mais "líquidas" e mais diverso, e que, ao mesmo tempo, vê emergir discursos nacionalistas, sectários e conservadores.

Ainda que não exista um consenso sobre a definição do termo Estudos Culturais, trata-se de estudos,

[...] tipicamente interpretativos e avaliativos em suas metodologias [...] eles rejeitam a equação exclusiva da cultura como alta cultura e argumentam que todas as formas de produção cultural precisam ser estudadas em relação a outras práticas culturais e às estruturas sociais e históricas. Os estudos culturais estão, assim, comprometidos com o estudo de todas as artes, crenças, instituições e práticas comunicativas. (Nelson et al., 1995, p.12)

Os Estudos de Mídia (Media Studies) se associam a esta corrente dos estudos culturais e buscam investigar as relações entre a mídia e a sociedade, tendo como objeto de estudo, entre outros, as audiências, a recepção e a produção midiática (TV, internet, redes sociais, cinema, música, jornais, revistas etc). É no interior dos Estudos de Mídia que localizamos a nossa discussão em torno da relação que o público estabelece com os filmes e a relação que os produtores de filmes buscam estabelecer com seus públicos, por meio de suas obras. Dentro desta reflexão, torna-se central o conceito de endereçamento ou de modos de endereçamento.

Neste artigo, teórico-analítico, pretendemos apresentar o conceito de endereçamento e suas implicações para a prática educacional, nos campos da educação científica e tecnológica e da extensão rural, baseados em algumas questões introdutórias que guiarão a reflexão, a saber:

a) O que é o endereçamento de vídeos? 
b) Quais evidenciam que atestam a real existência de um endereçamento de obras audiovisuais? Ou seja, como o endereçamento se manifesta?

c) Sempre existe um endereçamento?

d) O endereçamento é uma construção intencional?

Contextualmente, esta reflexão está circunscrita a uma pesquisa de Doutorado Interinstitucional (Dinter), realizada no Instituto Nutes de Educação em Ciências e Saúde da Universidade Federal do Rio de Janeiro. A pesquisa tem como locus o Ifes campus Piúma, dedicado à área dos recursos pesqueiros com cursos técnicos em Aquicultura e Pesca e bacharelado em Engenharia de Pesca, todos pertencentes à grande área das Ciências Agrárias. Essa pesquisa de doutorado tem como objeto de estudo a produção de vídeos por discentes para a aplicação na Extensão Rural.

O artigo busca apresentar um conceito de endereçamento e, a partir disto, ressignificar sobre o uso de audiovisuais na Educação Científica e Tecnológica a partir do paradigma do espectador-educando.

\section{METODOLOGIA}

Utilizando a própria teoria dos modos de endereçamento como referencial metodológico, buscamos explicar o que seria o endereçamento e destacar a sua importância para a prática de produção de vídeos educacionais, pois a análise dos modos de endereçamento nos permite pensar e compreender de forma mais aprofundada como um filme ${ }^{1}$ se relaciona com a sua audiência, ou seja, possibilita perceber como um filme é endereçado.

A partir disto, é possível ressignificar a prática da produção audiovisual educacional, a partir do paradigma da Recepção Audiovisual. A proposta é pensar esta 
produção na perspectiva de quem será o espectador e de quais reações são esperadas e estimuladas neste mesmo espectador.

De acordo com o semiótico britânico Daniel Chandler, no texto Semiotics for Beginners,

São fatores relacionados ao modo de endereçamento o contexto textual, que inclui as convenções de gênero e a estrutura sintagmática, o contexto social, que diz da presença/ausência do produtor do texto, da composição da audiência, de fatores institucionais e econômicos, e os constrangimentos tecnológicos, que se referem às características de cada meio (1998 citado por Gomes, 2011).

Estes fatores, elencados pelo autor, são exemplos de operadores de análise do modo de endereçamento que nos permitem entender o próprio conceito de endereçamento, como o expomos neste artigo.

Sendo assim, trata-se de uma pesquisa qualitativa com articulações teóricopráticas que podem implicar novas interpretações do uso dos audiovisuais no campo da Educação Científica e Tecnológica. Por meio da discussão e da análise do modo de endereçamento de algumas produções audiovisuais, procuramos evidenciar nuances mais destacadas do fenômeno do endereçamento e sua importância no processo de concepção e produção dessas obras audiovisuais.

\section{RESUlTAdOS E DisCUSSÃO}

O arcabouço teórico deste artigo tem como base a teoria dos modos de endereçamento compilada e elaborada por Elizabeth Ellsworth (2001), publicada no Brasil como um capítulo na obra "Nunca fomos humanos", sob o título "Modos de endereçamento: uma coisa de cinema; uma coisa de educação também". 
Em suas obras, Ellsworth ${ }^{2}$ analisa questões relacionadas ao ensino, a partir de campos, a princípio, vistos como não pedagógicos, como as áreas de comunicação, teoria literária e cinema. Em sua concepção,

O modo de endereçamento de um filme tem a ver, pois, com a necessidade de endereçar qualquer comunicação, texto ou ação "para" alguém. E, considerando-se os interesses comerciais dos produtores de filme, tem a ver com o desejo de controlar, tanto quanto possível, como e a partir de onde o espectador ou a espectadora lê o filme. Tem a ver com atrair o espectador ou a espectadora a uma posição particular de conhecimento para com o texto, uma posição de coerência, a partir da qual o filme funciona, adquire sentido, dá prazer, agrada dramática e esteticamente, vende a si próprio e vende os produtos relacionados ao filme. (Ellsworth, 2001, p. 24)

Por definir como os filmes serão vistos, a que públicos se dirigem e como serão aceitos, adaptados ou rejeitados pelos públicos aos quais se dirigem, o modo de endereçamento irá mobilizar e interferir na escolha dos produtores, em torno dos elementos nos âmbitos técnico, estético e dramatúrgico, no decorrer de uma produção audiovisual.

Por exemplo, se o objetivo é endereçar um filme para crianças pequenas, ainda em idade pré-escolar, é comum a utilização de cores fortes e primárias. Não é uma regra, mas é uma escolha estética que responde ao contexto atual que não faria sentido quando predominavam na sociedade os aparelhos de TV preto e branco. Este fato já havia sido destacado por Kaitlin Brunick e James Cutting (2014), no capítulo Coloring the Animated World: Exploring Human Color Perception and Preference through the Animated Film, no qual refletiam sobre a recepção de filmes de animação por adultos e crianças e sua relação com as cores. De acordo com os autores,

os níveis de saturação [das cores] nos filmes infantis provavelmente refletem a preferência das crianças pequenas por cores brilhantes. No entanto, é improvável que os cineastas estejam conscientemente fazendo essas escolhas com base na literatura psicológica; os cineastas provavelmente estão intuindo essa preferência, talvez com base em suas próprias concepções de como as crianças respondem ao cinema ou a outras partes do ambiente visual. Independentemente da base dessa intuição, é importante

\footnotetext{
${ }^{2}$ Professora do Departamento de Estudos de Mídia e Cinema da The New School University (Estados Unidos).
} 
observar que as tendências de saturação nos filmes parecem corresponder às preferências cientificamente estabelecidas do público-alvo. (BRUNICK; CUTTING, 2014, p. 7)

Ao pensarmos sobre os modos de endereçamento, questionamos como os filmes, que são direcionados a um determinado público, foram pensados e produzidos para atender às expectativas deste referido público, ou seja: quem o filme pensa que o público é? Como os seus produtores interpretam esse público? Quais estratégias narrativas usam ou deixam de usar para conquistar e/ou atingi-lo? Pois, de acordo com Ellsworth,

a maioria das decisões sobre a narrativa estrutural de um filme, seu acabamento e sua aparência final são feitos à luz de pressupostos conscientes e inconscientes sobre "quem" são seus públicos, o que eles querem, como eles veem filmes, que filmes eles pagam para ver no próximo ano, o que os faz chorar ou rir, o que eles temem e quem eles pensam que são, em relação a si próprios, aos outros e às paixões e tensões sociais e culturais do momento. (ELLSWORTH, 2001, p. 14)

A autora também destaca que, em um primeiro entendimento dos teóricos da área, o modo de endereçamento fazia referência a um conjunto de elementos que estariam no texto fílmico. No entanto, em entendimento posterior, eles passaram a afirmar que

o evento do endereçamento ocorre num espaço que é social, psíquico, ou ambos, entre o texto do filme e os usos que o espectador faz dele. Essa mudança, [...] deixa de localizar o modo de endereçamento no interior do texto de um filme e passa a compreendê-lo como um evento. (ELLSWORTH, 2001, p. 13)

Este fato pode ser ilustrado pelo exemplo citado anteriormente a respeito dos filmes e programas infantis. A não existência de TV em cores não é algo que está diretamente no texto fílmico, mas algo que está nas características do meio tecnológico escolhido para a "transmissão" da mensagem, assim como a preferência das crianças por cores não é algo que diz respeito diretamente ao texto fílmico, mas à constituição psíquica do indivíduo e, portanto, ao contexto social. 
Por outro lado, é preciso reconhecer também a existência das marcas de endereçamento, como as exemplificadas por Valerio Fuenzalida (2008) em artigo que discute as mudanças na relação das crianças com os programas de televisão. Ao apresentar as marcas de endereçamento, o autor destaca que

os novos programas [infantis] representam simbolicamente as crianças em um papel ativo e de liderança, realizando atividades e tarefas em que são exibidas como capazes de iniciativa criativa e solução inteligente de problemas; as séries animadas "Bob, o construtor" e "Dora, a aventureira" são emblemáticas dessas mudanças. (FUENZALIDA, 2008, p. 50)

No mesmo sentido, Chandler (1998) afirma que os modos de endereçamento se inter-relacionam a três fatores, a saber: o contexto textual, o contexto social e as restrições tecnológicas. Entre esses, o contexto textual ${ }^{3}$ diz respeito às convenções de cada gênero textual e de cada estrutura sintagmática4. Já o contexto social diz respeito a "fatores econômicos, institucionais, escala e composição da audiência" (Rezende Filho et al., 2013, p. 3) e as restrições tecnológicas dizem respeito às características do meio empregado (escrito, falado, televisivo, fílmico, iconográfico etc).

A partir destes autores e pensando nas produções audiovisuais, constatamos que os modos de endereçamento conjugam um conjunto de escolhas nos âmbitos técnico, estético e dramatúrgico, feitas no decorrer de uma produção audiovisual e expressas ou não no texto fílmico. Estas escolhas levam em consideração o contexto textual, o contexto social e as restrições tecnológicas do meio e partem de pressupostos, ora conscientes, ora inconscientes, a respeito de quem é o público pelo olhar dos produtores. Estas escolhas se manifestam por meio de elementos ou marcas de endereçamento que podem ser identificadas no texto fílmico, no contexto de exibição e no estudo da recepção da obra audiovisual, de forma inter-relacionada. As

\footnotetext{
${ }^{3}$ Cabe destacar que o autor não reflete apenas sobre obras audiovisuais. Ele se refere a construções textuais em geral, independe do meio de suporte.

${ }^{4}$ Sintagma é o conjunto de palavras subordinadas aos núcleos das orações. Como toda oração é formada pelo sujeito + predicado, o estudo do sintagma é uma análise do sentido e da função das palavras que acompanham justamente o núcleo desse sujeito e o núcleo desse predicado. (wikibooks).
} 
marcas de endereçamento conferem "materialidade" aos modos de endereçamento e são, portanto, sua face mais visível.

Talvez nesse momento a questão da real existência do endereçamento de obras audiovisuais e, se existe, como ele se manifesta. Estas questões só podem ser respondidas por meio da análise de casos que nos fornecem alguns indícios que nos permitam inferir a existência do endereçamento.

Um primeiro caso a analisar é o fato de existir um campo de estudos dedicado à forma como as pessoas recebem e/ou reagem às obras audiovisuais. Essa área de estudo, dentro do campo da comunicação e dos estudos culturais, é conhecida como Estudos de Recepção. De acordo com a Enciclopédia Intercom de Comunicação, a recepção

se refere a processos conscientes e lógicos de atenção, interpretação, compreensão ou mera exposição à mídia, ou a processos valorativos como a aceitação ou gosto. A maioria das pesquisas de recepção tomam a televisão como seu objeto de estudo, problematizando-se a formação dos gostos, os prazeres do consumo, as representações identitárias, a sociabilidade, assim como questões políticas vinculadas à criação de consensos hegemônicos. (NATANSOHN, 2010, p. 1028)

Um exemplo clássico de Estudo de Recepção foi aquele realizado pelo Centre for Contemporany Cultural Studies da Universidade de Birminghan (Inglaterra), com a participação do Prof. David Morley, acerca do programa televisivo de variedades Nationwide, da British Broadcasting Corporation (BBC), entre 1975 e 1979. Seguindo o método de análise de Morley (1996), que conjugava a semiótica com a sociologia, o estudo buscou evidenciar: a) as marcas de endereçamento (formas específicas de se dirigir à audiência e de organização textual), e b) a interpretação que os indivíduos de diferentes grupos sociais (faixa etária, sexo, raça e classe social) faziam do programa.

A pesquisa exibiu o programa para grupos que o discutiam na sequência, com o objetivo de identificar temas recorrentes e formatos de apresentação dos episódios. A partir disto, evidenciaram-se posições de aceitação, de rejeição e de negociação que a 
audiência realizava em torno das posições defendidas/apresentadas pelo programa. 0 estudo concluiu que as interpretações pessoais e os consequentes posicionamentos variavam de acordo com os seguintes fatores: sociodemográficos (idade, sexo, raça e classe); culturais (consciência de classe, posições políticas, identificação com minorias etc.); temáticos (abstratos e concretos) e contextuais (contexto de exibição escolar, laboral ou familiar). Ou seja, alguns grupos pesquisados tendem a ter uma interpretação e um posicionamento mais próximo ao esperado pelos produtores, sendo classificados em um posicionamento chamado de dominante, mais próximo do significado preferencial pensado para o programa. Outros grupos apresentaram um posicionamento de rejeição ou de negociação diante da leitura preferencial ${ }^{5}$ esperada pelos produtores. Ambos os casos demonstram que, além das questões de compreensão e posicionamento político-ideológico intervenientes na leitura do programa, existe também um endereçamento que, por vezes, "acerta" e por vezes "erra" o seu público. "Acertando" ou "errando", demonstra-se, assim, que existem públicos definidos para um determinado programa, o que reafirma a existência de um endereçamento.

Outro caso que nos leva a afirmar a existência do endereçamento é o fato de alguns produtores buscarem ajustá-lo para agradar mais a seu público ou para atingir um público mais variado, por meio do que podemos chamar de camadas de endereçamento. Isso é visível em diversas produções, mesmo que os produtores não afirmem claramente que têm esse intuito.

Para ilustrar, podemos tomar o exemplo do filme Toy Story 4. Lançado em junho de 2019, com direção de Josh Cooley e produção da Disney, em parceria com a Buena Vista. A animação conta a história de brinquedos que ganham vida e se envolvem em

\footnotetext{
${ }^{5}$ A leitura preferencial é a tentativa dos produtores de obras audiovisuais, programas televisivos, peças publicitárias e congêneres de exercer o controle da significação a ser estabelecida pelo espectador, como se dissessem a este "leia-me desta forma". (cf. BASTOS, 2014, p. 20) 
aventuras. Dada a data de lançamento do filme (férias escolares nos Estados Unidos), a classificação indicativa livre e a infinidade de produtos comerciais infantis associados aos personagens, podemos afirmar que se trata de um filme endereçado para crianças. No entanto, os produtores buscam atingir outros públicos, utilizando recursos estéticos, técnicos e dramatúrgicos específicos para esses públicos. Por exemplo, como vivemos em um cenário de empoderamento feminino e crescimento do feminismo no mundo, os produtores respondem a este fenômeno inserindo na trama uma personagem feminina, que já havia aparecido em filmes anteriores da franquia como coadjuvante. Agora, porém, ela é apresentada sob uma nova perspectiva. Este fato foi destacado pelo jornalístico Fantástico ${ }^{6}$. De acordo com a reportagem,

Tem uma garota que andava sumida e que promete roubar a cena. E ela também está bem diferente. No primeiro filme Betty Bo-peep era só uma bonequinha que fazia parte de um abajur. Uma pastora de ovelhas, delicada, de porcelana, mas virou um brinquedo sem dono por opção, um brinquedo perdido no mundo e que sabe se defender. Os diretores dizem que já estava na hora de desenvolver uma personagem feminina com espaço de protagonista. "Ela é malandra e chegou a vez de ela brilhar. Ela sempre foi uma personagem forte, mas a gente queria deixar ela ainda mais empoderada." (Fantástico, 2019)

Da mesma forma, os produtores afirmam que inseriram no filme brinquedos de várias gerações, buscando atingir um público mais variado, ou seja, adaptaram as camadas de endereçamento para gerar identificação em públicos diferentes daquele pensado para o endereçamento principal. De acordo com a reportagem,

Os criadores contam que foram buscar inspiração em seus próprios brinquedos de infância e que várias gerações estão representadas no filme. "A gente espera que todo mundo, você, os seus pais e seus filhos, vejam brinquedos da própria infância e se identifiquem" (Fantástico, 2019)

Existem, também, os casos nos quais o endereçamento "erra", ou seja, casos nos quais as pressuposições dos produtores sobre seus públicos os levam a criar narrativas que estigmatizam o público, o infantilizam, o subestimam, supõem que o público sabe

\footnotetext{
${ }^{6}$ Programa jornalístico da Rede Globo de Televisão, em reportagem de 17/06/2019 intitulada "Animador brasileiro ajudou a dar vida ao personagem central de 'Toy Story 4'"
} 
mais ou menos do que de fato sabem e acabam por não se dirigir exatamente ao público para o qual a obra audiovisual foi supostamente endereçada.

Um caso emblemático é o da série "Olhos que condenam" (When they see us), da plataforma de streaming Netflix. Com direção de Ava DuVernay, a série retrata os acontecimentos ligados à condenação de cinco jovens negros que foram falsamente acusados do estupro de uma mulher no Central Park em 1989. A carreira da diretora é marcada por produções que tratam da temática da discriminação racial, tais como o filme "Selma", que narra a história da luta de Martin Luther King Jr., e o documentário "A 13믈 Emda", que apresenta a discussão em torno do encarceramento em massa de negros americanos. Esse histórico nos permite supor que a diretora, mulher negra americana, endereçou a sua série para um público negro. Vejamos o que a própria diretora disse sobre o endereçamento de seu filme e a exibição para as pessoas reais que inspiraram a história:

Foi importante para mim, uma vez terminada a série, mostrar essa história real aos homens. Eu queria que todos vissem, mas especialmente eles, porque se tratava deles e de suas famílias. Eu estava nas minhas últimas pernas, mas nós os trouxemos para a Netflix, eles assistiram e eu os assisti. Sentei-me atrás deles em uma sala de exibição de duas fileiras. Eu não estava assistindo a tela. Eu estava observando os rostos deles. [...] Foi uma experiência que nunca mais terei, porque simplesmente não pode ser duplicada. As pessoas reais, você trabalhou em uma história por quatro anos, fizeram esta filmagem que você pensou que não poderia fazer. Você editou, tentou encontrar uma maneira de manter as pessoas interessadas em uma história sobre cinco meninos de cor e injustiça o suficiente para que talvez algumas pessoas assistam e gostem. E você termina, e eles te abraçam e choram, e dizem: "Você conseguiu". Foi esse momento que fez tudo valer a pena. (PATTEN, 2019)

De fato, a série atingiu uma grande audiência ${ }^{7}$, no entanto, foi rejeitada por parte do público negro por chocar mais do que motivar ${ }^{8}$. No Brasil, a crítica de Dodô Azevedo

\footnotetext{
723 milhões de visualizações mundialmente, em menos de um mês (Site Adoro cinema).

8 "Assisti a 20 minutos de 'Olhos que Condenam' e parei", diz Lázaro Ramos - Folha de São Paulo - 4 jul. 2019. https://www1.folha.uol.com.br/ilustrada/2019/07/assisti-a-20-minutos-de-olhos-que-condenam-e-parei-diz-lazaroramos.shtml.
} 
na Folha de São Paulo, intitulada "Recusa a ver 'Olhos que Condenam' pode ser um ato revolucionário" ilustra uma posição de rejeição à série, vejamos:

Se há quem esteja evitando assistir à série, como, então, ela é a mais vista da história da plataforma? Somos, no mundo, uma espécie fascinada por sofrer assistindo ao sofrimento do outro. Somos aqueles que, tendo nos perdido de vista, desejamos ver na marca de nossa ausência o olhar do outro, em que, eventualmente, nossa presença possa surgir.

E aqui vivemos no país de filmes como "Tropa de Elite" e "Cidade de Deus", por exemplo, nos quais o sofrimento do negro nos eletriza em vez de nos traumatizar.

Mas há o que o sempre inspirado Igor Verde, jovem roteirista brasileiro e negro, chama de "narrativas que projetam novas possibilidades de vida". Entre os musicais brasileiros, são os que contaram as vidas de Elza Soares e de Dona Ivone Lara. Na televisão, programas como "Mister Brau". Nos Estados Unidos, o luminoso "Guava Island", filme que Childish Gambino produziu com Rihanna em Cuba. Ou Spike Lee, com os seus longas-metragens "Faça a Coisa Certa" e "Infiltrado na Klan", que nos fazem chorar - e também rir. (AZEVEDO, 2019)

A partir desta crítica e amparados nas teorias do endereçamento, destacamos que as escolhas estéticas e dramatúrgicas da diretora fizeram com que parte do público negro entendesse que aquilo não lhe diz respeito ou não se direciona a ele. Na interpretação do crítico Dodô Azevedo, as escolhas da diretora visavam a ir contra a construção de um discurso positivo sobre as possibilidades de superação do racismo e de demais opressões/exclusões vividas pela comunidade negra. Mesmo sendo uma série dirigida por uma mulher negra com histórico de produções em favor da causa dos negros, que discute o racismo a partir de um caso emblemático, endereçada para um público, partidária da luta dos negros.

Se o crítico estiver certo em sua análise, o grande número de visualizações da série é um sintoma de uma sociedade fascinada pelo sofrimento, o que apresenta um elemento a mais na reflexão sobre o modo de endereçamento. Se assim for, mesmo tendo sido a série produzida com um endereçamento claro e favorável à identificação do público negro, ela é aceita por outros públicos, que a leem com outros objetivos e de outra perspectiva que não só a da indignação com a injustiça ou da luta antirracista. 
Isso nos mostra que os públicos também podem se adaptar aos modos de endereçamento.

Casos como os citados acima, de estudos de recepção, de ajustes e de "erros" no endereçamento são comuns e poderiam ser atualizados com grande frequência. Estes casos não são provas irrefutáveis da existência do endereçamento, nem é esse o nosso objetivo. No entanto, eles são fortes indicadores que nos permitem inferir que existe o endereçamento, ainda que por vezes ele não seja completamente aceito e visível pelo público ao qual se dirige, ou que seus produtores busquem apagar seus rastros, na suposição e intento de dirigir-se a todos.

\subsection{DIMENSÃo PolítICA DO ENDEREÇAMENTO}

É importante destacar que existe uma dimensão política na análise e na produção dos modos de endereçamento, sobretudo se levarmos em consideração que não se pode pensar o modo de endereçamento fora da dinâmica social e das relações de poder. De acordo com Ellsworth,

O modo de endereçamento não é um conceito neutro na análise cinematográfica. Trata-se de um conceito que tem origem numa abordagem de estudos do cinema que está interessada em analisar como o processo de fazer um filme e o processo de ver um filme se tornam envolvidos na dinâmica social mais ampla e em relações de poder. Embora os públicos não possam ser simplesmente posicionados por um determinado modo de endereçamento, os modos de endereçamento oferecem, sim, sedutores estímulos e recompensas para que se assumam aquelas posições de gênero, status social, raça, nacionalidade, atitude, gosto, estilo às quais um determinado filme se endereça. (Ellsworth, 2001 p. 24)

Esta abordagem de estudos de cinema à qual Ellsworth (2001) faz referência é a abordagem dos estudos culturais que investiga a produção, a criação e a difusão dos significados que o ser humano atribui às suas ações as outros, a partir da vivência social. Sendo assim, conforme destacado pela autora, ganham destaque nesta análise os conceitos de dinâmica social e de relações de poder. 
Ao considerarmos a dinâmica social, buscamos entender como a sociedade muda, por que muda e em benefício de quem ela muda. Já, ao pensarmos as relações de poder, buscamos entender o que leva alguém a seguir as determinações ou a se sujeitar às determinações de outros, bem como destacar qual a origem desse poder (econômico, ideológico ou político).

Ao pensarmos sobre "quem esse filme quer que eu seja", estamos a pensar na dinâmica social, posto que envolve uma expectativa de mudança de pensamento ou de atitude e também estamos pensando nas relações de poder, pois essas mudanças são o desejo de alguém ou de alguma classe, que quer que seus valores sejam os hegemônicos.

Exemplos de programas televisivos, propagandas e filmes que desejaram mudar ou moldar comportamentos não faltam na história, desde os primórdios do cinema, seja com objetivos políticos, ideológicos ou comerciais, como os filmes americanos da década de 1940-50, que destacavam o American way of life, ou os filmes produzidos pelo departamento de propaganda nazista. Os filmes e, consequentemente, seus modos de endereçamento não são neutros.

Em artigo intitulado “Educação em saúde e vídeo: o endereçamento como uma questão educacional", Rezende et al. (2013) apontam estas questões, de maneira mais palpável e mais próxima de nossa realidade, ao analisar o endereçamento de 14 vídeos de educação em saúde. De acordo com os autores,

A análise do endereçamento produziu dados que ajudaram a compreender melhor como os vídeos constroem seus espectadores e assim ajudam a melhor utilizá-los na educação médica e educação em saúde. A forma como os personagens são construídos não revela apenas aspectos sobre quem os vídeos pensam que são seus espectadores, mas também sobre quem eles querem que os espectadores sejam. Os vídeos são em geral muito enfáticos sobre como eles esperam que os espectadores pensem, ajam e sejam após a exibição. (Rezende et al., 2013, p. 118) 
Já no campo da Ciências Agrárias, que é nosso objeto de pesquisa, podemos ilustrar com a análise das escolhas estéticas e dramatúrgicas (marcas de endereçamento) presentes no programa de Jornalismo Rural intitulado "Globo Rural", da Rede Globo de Televisão, por meio da análise realizada por Jussara Maia (2011) em artigo intitulado "Globo Rural: ao estilo da cultura do campo". De acordo com a autora,

As marcas do diálogo e da participação são exploradas intensamente nas reportagens feitas por eles [os repórteres]. Todos possuem, com mais ou menos intensidade, uma locução marcadamente pausada para acentuar o tom dialógico da reportagem e do programa. Com trajes ajustados ao ambiente em que gravam as imagens e entrevistas, eles se vestem de modo despojado, simples, com calças jeans e camisas em tons claros com as mangas dobradas, bem distintos dos paletós e blazers usados pelos repórteres dos telejornais. Muitas vezes, recorrem ao uso de botas para se adequarem ao local, quando estão em mata fechada ou regiões alagadas. (Maia, 2011, p. 105)

São ainda destacados pela autora exemplos de escolhas técnicas que também atuam no endereçamento.

Quase sempre, quando [os repórteres] aparecem no vídeo (em abertura, passagem ou encerramento), não utilizam o microfone direcional, predominante nos telejornais, que, por serem visíveis, destacam o papel mediador da tecnologia empregada na televisão. Mais frequentemente, utilizam o microfone boom (usual nas gravações para o cinema) que fica preso a uma haste móvel acima da cabeça das pessoas que participam da entrevista, sem ficar exposto. No enquadramento, é oferecida para o telespectador uma terceira posição entre o repórter e o entrevistado na "conversa" encenada, a de um participante pressuposto. (Maia, 2011, p. 105)

Até mesmo a pauta do programa e os temas escolhidos para serem desenvolvidos podem ser considerados uma marca de endereçamento, pois são temas de interesse de pequenos, médios ou grandes produtores que detêm a posse da terra, tais como a possibilidade de mudanças estruturais nas formas de cultivo (intensivo, extensivo ou semi-intensivo, por exemplo), as alterações em edificações ou na rotina de trabalho dos colaboradores, o atendimento às normas ambientais relativas às reservas legais de mata nativa etc. Questões como essas não se direcionam, portanto, 
aos funcionários do empreendimento agrícola, que não têm a propriedade da terra e não estão envolvidos com os mesmos problemas e decisões do proprietário.

Tal materialidade do endereçamento do Globo Rural nos mostra que a expressão "homem do campo", usada pelos produtores do programa para definir seu público, é bastante tencionada pelos outros homens, e mulheres, do campo que dela estão de fato excluídos, conforme destaca Maia (2011), ao afirmar que

[...] o programa se endereça à cultura própria do homem do campo de qualquer parte do país e, dessa forma, modela suas escolhas nos mínimos detalhes. Mas o mundo reconfigurado pelas escolhas de abordagem dos assuntos revela nuances que favorecem a identificação do homem do campo mais restrito às regiões do país onde o desenvolvimento tecnológico, que foi apagado lá do aspecto visual do programa, foi empregado para industrializar os sistemas de plantio, colheita e comercialização. [...] Por isso, o referencial de homem do campo endereçado pelo Globo Rural não é, preferencialmente, aquele típico do interior do Norte e Nordeste, sozinho, adepto da agricultura familiar, distante da estrutura organizada das cooperativas, desprovido de escolaridade e cheio de dificuldades para desenvolver sua produção. Este, quando aparece, é para exemplificar os desacertos em contraposição com os casos de outros agricultores, mais bem-sucedidos, que souberam buscar o apoio dos especialistas em institutos de pesquisa, universidades e órgãos públicos. (Maia, 2011, p. 118)

Sendo assim, apesar de conseguir se comunicar com o "homem do campo" de modo mais geral, o programa se endereça ao homem do campo pensado na perspectiva do agronegócio, afetado pelo processo de mecanização do trabalho com a introdução de novas tecnologias e maquinário. Não apresenta, portanto, uma visão neutra. Politicamente, o programa corrobora uma visão de "homem do campo" já construída (quem eles pensam que o público é) ou em vias de construção (quem eles querem que o público seja).

\subsection{ENDEREÇAMENTO E EXTENSÃO RURAL}

Após esta breve incursão sobre os pressupostos básicos do endereçamento, passamos a apontar a possibilidade de contribuição que o conhecimento em torno 
deste conceito pode trazer para a produção de vídeos para a aplicação na Educação Científica e Tecnológica, principalmente no campo das Ciências Agrárias.

A produção de vídeos educacionais de orientação técnica é uma das formas de se atuar na Extensão Rural. No contexto das Ciências Agrárias, esses vídeos são utilizados por várias instituições públicas e particulares para a introdução de novas práticas de produção e manejo, divulgação de normas ambientais ou de produção, reflexão em torno de novos arranjos laborais e produtivos ou mesmo para tirar as dúvidas pontuais dos produtores de uma determinada cultura ou região.

Sendo assim, os vídeos para a orientação técnica pressupõem uma posterior tomada de atitude ou mudança de comportamento, visando a melhorias na produção. Eles ultrapassam a barreira meramente informacional, pois além de informar, também visam a educar. É necessário, portanto, que os produtores desses vídeos estejam atentos a quem é o público para o qual se dirigem e que informações têm sobre esse público. Exige, portanto, a construção de estratégias de endereçamento, o qual realizado a partir de pressuposições, quase sempre e, inevitavelmente, mais ou menos limitadas e estereotipadas sobre quem é o público. De acordo com Rezende Filho et al. (2013, p.3),

As pressuposições que os filmes fazem sobre as identidades e conhecimentos de seus espectadores os estimulam a tomarem posições frente a situações concretas, ainda que fictícias, que Ihes são apresentadas nos filmes. Tal situação coloca para o espectador a pertinência e o desejo de levar ou não a experiência vivida para o campo da ação e da prática social ou incorporar ao imaginário e à subjetividade elementos trazidos por ela. (Grifo nosso)

No campo da educação com audiovisual, o endereçamento é ponto chave para que o espectador se reconheça como sujeito do processo de aprendizagem proposto pelo material educativo e, assim, se posicione diante do que lhe é apresentado, ainda que em uma posição de resistência. Quando Elizabeth Ellsworth (2001) afirma que o modo de endereçamento é uma coisa de cinema, mas também é uma coisa de Educação, ela está alertando para refletirmos sobre qual público pensamos para as 
nossas práticas educacionais; como pensamos esse público e, ainda, quais estratégias usamos para cativá-lo. Em torno disso, aparecem as questões relacionadas aos erros no endereçamento e aos espaços de aceitação, negociação e rejeição que esta situação acaba por criar. De acordo com Ellsworth (2001, p.12)

Se você compreender qual é a relação entre o texto de um filme e a experiência do espectador, por exemplo, você poderá ser capaz de mudar ou influenciar, até mesmo controlar, a resposta do espectador, produzindo um filme de uma forma particular. Ou você poderá ser capaz de ensinar os espectadores como resistir ou subverter quem um filme pensa que eles são ou quem um filme quer que eles sejam.

Neste sentido, a reflexão em torno do endereçamento pode contribuir para a produção de novos vídeos, já que pode mudar, influenciar e, até mesmo, "controlar" a resposta do espectador, desde que haja uma identificação entre o espectador ideal pensado pelo produtor e este espectador real.

Esta não é tarefa fácil. Não há uma fórmula, mas um trabalho de construção do endereçamento que se torna mais complexo à medida em que o produtor de vídeos dispõe de mais recursos e conhece mais seu público. Portanto, não é aconselhável se aventurar-se em uma produção de vídeo para a orientação técnica sem a clareza em torno do público e das relações que ele estabelece com o mundo à sua volta, incluindo, aí, como ele acessa e se apropria das obras audiovisuais.

Eventualmente, os filmes "erram" o endereçamento, ou seja, por vezes as pressuposições do produtor em torno do seu público não correspondem ao público real e não permitem que esse assuma as posições esperadas. O mesmo pode acontecer em vídeos para a aplicação na orientação técnica, desde que o que seja apresentado não corresponda à realidade do(a) produtor(a) rural que assiste ao vídeo.

Por exemplo, um grande produtor do agronegócio dificilmente espera contar com orientações técnicas em vídeo, pois já conta com uma equipe capacitada para isso, o que nos leva a acreditar que o público primordial dos vídeos de orientação 
técnica sejam os pequenos e médios produtores. Neste sentido, mostrar a colheita mecanizada de extensas áreas de soja com grande maquinário em um vídeo será apenas informativo para um público de pequenos e médios produtores, posto que não se endereça ao produtor que conta com colheita manual, em pequenas e médias propriedades.

Sendo assim, a reflexão sobre a construção do endereçamento de vídeos educacionais, seja para a aplicação no Ensino seja para a aplicação na Extensão apresenta-se como um elemento de aprimoramento das produções audiovisuais no campo da Educação Científica e Tecnológica. Desta forma, possibilitam que essas obras audiovisuais, como materiais didáticos, possam ampliar sua capacidade de atingir os objetivos educacionais inerentes a cada prática na qual são aplicados, tendo sempre como guia a leitura que se espera ser feita pelo espectador e os parâmetros de análise oferecidos pelos estudos de recepção.

\section{CONSIDERAÇÕES FINAIS}

O produtor audiovisual conjuga um conjunto de escolhas nos âmbitos técnico, estético e dramatúrgico, no decorrer da sua produção, para construir o que é conhecido como endereçamento, no campo do audiovisual, com o objetivo de conquistar e/ou atingir o seu público. O público, por sua vez, pode aderir ou não à mensagem, o que pode ser detalhado com um estudo de recepção.

Eventualmente, produtores optam por atingir públicos variados, como no caso da animação Toy Story 4, ainda que com a prevalência de um "público-alvo", ou buscam fazer uma obra mais voltada para um público específico, como no caso da série "Olhos que condenam" (When they see us). Em ambos os casos, a análise dos modos de endereçamento pode revelar as concepções dos produtores sobre quem eles pensam que o público é, ou sobre quem eles querem que o público seja. 
Com isso, destacamos que o endereçamento tem uma dimensão política, pois pressupõe que o público é estimulado a olhar a produção audiovisual de uma determinada forma, de um lugar especialmente construído, o que revela as relações de poder que interferem na dinâmica social de espectadores.

Análise dos modos de endereçamento ou a construção do endereçamento de uma obra audiovisual não podem, sozinhas, expressar toda a complexidade da dinâmica social e das relações de poder que um filme pode veicular. São apenas mais uma das várias categorias de análise e metodologias das quais se valem os teóricos dos Estudos Culturais ou dos Estudos de Mídia para ilustrar a intricada teia comunicacional e de significações da qual todos participamos, direta ou indiretamente.

Destacamos que grande parte das escolhas realizadas pelos produtores na construção do endereçamento de seus filmes são inconscientes, ou seja, não foram racionalmente elaboradas, sendo reflexo da organização social e da constituição psíquica do produtor audiovisual. Sendo assim, não é possível afirmar que cada marca de endereçamento seja sempre atenciosamente pensada, pois pode apenas ocupar um lugar comum e implícito na sociedade na qual a obra foi produzida e, mesmo assim, expressar concepções sobre o público circulantes na sociedade. Buscar um distanciamento visando a perceber essas marcas, e realizar a análise dos modos de endereçamento nos parece um bom caminho para a quebra de preconceitos e de paradigmas que perduram nas obras audiovisuais, que acabam por reforçá-los. Essa é uma questão mais ampla que não poderíamos deixar de apontar, mesmo tendo a clareza de que não poderemos aprofundá-la.

Despertar um conhecimento introdutório sobre o tema do endereçamento se faz necessário, antes de qualquer análise mais aprofundada. Este foi o objetivo deste artigo, ou seja, apresentar o conceito de endereçamento, desejando encantar (ou assombrar) pelo fenômeno do endereçamento, de modo a estabelecer novas relações 
com as obras audiovisuais e seus usos/desusos, principalmente no campo da Educação.

Aos Extensionistas, Técnicos e Educadores que lidam com os homens e as mulheres do campo, em ações de assistência técnica, orientação ou Extensão Rural, convidamos a lançar um olhar mais acurado sobre os vídeos que venham a produzir e/ou utilizar em suas estratégias de Educação junto às comunidades rurais. Afinal, será mesmo que todo "o Agro é tech"9? Será mesmo que todo o "Agro é Pop"?

\section{AGRADECIMENTOS}

O presente trabalho foi realizado com apoio da Coordenação de Aperfeiçoamento de Pessoal de Nível Superior - Brasil (CAPES) - Código de Financiamento 001 e dos editais CNPq № 12/2017 - Bolsas de Produtividade em Pesquisa (CNPq) e Auxílio à Pesquisa APQ 1 (FAPERJ).

\footnotetext{
${ }^{9}$ Referência à campanha publicitária da Rede Globo de Televisão, denominada "Agro: a Indústria-Riqueza do Brasil", que veicula spots durante a programação com o intuito de apresentar a visão dos produtores audiovisuais da empresa sobre as benesses do agronegócio no Brasil.
} 


\section{REFERÊNCIAS}

AZEVEDO, Dodô. Recusa a ver 'Olhos que Condenam' pode ser um ato revolucionário. Folha de São Paulo, São Paulo, 04 de jul. de 2019. Disponível em: https://www1.folha.uol.com.br/ilustrada/2019/07/recusa-a-ver-olhos-quecondenam-pode-ser-um-ato-revolucionario.shtml. Acesso em: 28 dez. 2019.

BASTOS, Wagner Goncalves. A produção de vídeos educativos por alunos da licenciatura em biologia: um estudo sobre recepção fílmica e modos de leitura. 2014 163 f. Tese (Doutorado em Educação em Ciências e Saúde) - Universidade Federal do Rio de Janeiro, Rio de Janeiro. 2014.

BRUNICK, Kaitlin; CUTTING, James. Coloring the Animated World: Exploring Human. Color Perception and Preference through the Animated Film. In: TABERHAM, P.; NANICELLI, T. Cognitive Media Theory. Oxford, UK: Oxford University Press. 2014.

CHANDLER, Daniel. Semiotics for beginners. 1998. Disponível em: http://visualmemory.co.uk/daniel/Documents/S4B/sem08b.html?LMCL=DfflxA\&LMCL=|blQkj. Acesso em: 04 de janeiro de 2020.

DEADLINE. 'When They See Us' Creator Ava DuVernay \& Emmy Nominated Cast Seek "Restorative Justice" In Central Park 5 Netflix Series. 2019. Disponível em: https://deadline.com/2019/08/when-they-see-us-ava-duvernay-emmys-central-parkfive-jharrel-jerome-niecy-nash-emmys-netflix-interview-1202670721/. Acesso em: 22 jan. 2020.

ELLSWORTH, Elizabeth. Modos de endereçamento: uma coisa de cinema: uma coisa de educação também. In: SILVA, Tomaz Tadeu. (Org). Nunca fomos humanos. Belo Horizonte: Autêntica, 2001.

FUENZALIDA, Valerio. Cambios en la relación de los niños con la televisión. Comunicar: Revista científica iberoamericana de comunicación y educación, n. 30, p. 49-54 2008.

G1. Animador brasileiro ajudou a dar vida ao personagem central de Toy Story 4. 2019. Disponível em: https://g1.globo.com/fantastico/noticia/2019/06/17/animadorbrasileiro-ajudou-a-dar-vida-ao-personagem-central-de-toy-story-4.ghtml. Acesso em: 05 jan. 2020.

GOMES, Itânia Maria Mota (org.). Gênero televisivo e modo de endereçamento no telejornalismo. Salvador: EDUFBA, 2011.

MAIA, Jussara. Globo Rural: ao estilo da cultura do campo. In: GOMES, Itânia Maria Mota (org.). Gênero televisivo e modo de endereçamento no telejornalismo. Salvador: EDUFBA, 2011.

MARTIN, M. A Linguagem Cinematográfica. São Paulo: Brasiliense, 2003. 
http://memoriaglobo.globo.com/programas/jornalismo/telejornais/globorural/fotos-e-videos.htm. Acesso em: 30 jul. 2018.

NELSON, C.; TREICHLER, P. A.; GROSSBERG, L. Estudos Culturais: uma introdução. In: SILVA, T. T. (Org.) Alienígenas na sala de aula: uma introdução aos Estudos Culturais em Educação. Petrópolis: Vozes, 1995.

RECEPÇÃO. In: ENCICLOPÉDIA Intercom de Comunicação. São Paulo: Sociedade Brasileira de Estudos Interdisciplinares da Comunicação, 2010.

REZENDE FILHO et al. Educação em saúde e vídeo: o endereçamento como uma questão educacional. In: IX ENCONTRO NACIONAL DE PESQUISA EM EDUCAÇÃO EM CIÊNCIAS - IX ENPEC. 2013. Rio de Janeiro. Atas do IX Encontro Nacional de Pesquisa em Educação em Ciências, 2013. Disponível em: http://www.nutes.ufrj.br/abrapec/ixenpec/atas/resumos/R1262-1.pdf. Acesso em: 09 jan. 2020.

REZENDE FILHO, Luiz Augusto Coimbra de (org). Reendereçamento e Legibilidade no uso do Audiovisual na Educação em Ciências e Saúde (Projeto de pesquisa). Rio de Janeiro: UFRJ, 2014.

REZENDE FILHO, Luiz Augusto Coimbra de et al. Contribuições dos estudos de recepção audiovisual para a educação em ciências e saúde. Alexandria: Revista de Educação em Ciência e Tecnologia, Florianópolis, v. 8, n. 2, p. 143-161, jun. 2015. Disponível em: https://periodicos.ufsc.br/index.php/alexandria/article/view/1982-

5153.2015v8n2p143/29500. Acesso em: 23 ago. 2019.

REZENDE FILHO, Luiz Augusto Coimbra; PEREIRA, Marcus Vinicius; PASTOR, Américo de Araújo. Estudo de Recepção de um Vídeo Sobre Refração da Luz Produzido por Alunos de Ensino Médio Como Atividade do Laboratório Didático de Física. Alexandria: Revista de Educação em Ciência e Tecnologia v. 5, n. 3, p. 165-180, 2012.

SILVA, Tomaz Tadeu (Org). Nunca fomos humanos. Belo Horizonte: Autêntica, 2001. 